\title{
Do 5 alpha reductase inhibitors decrease the risk of recurrent gross hematuria in patients who have had a transurethral prostatectomy?
}

\author{
Blayne Welk ${ }^{1,2,4}$; Jennifer Reid ${ }^{2}$; Michael Ordon ${ }^{2,3}$; Jeffrey Campbell ${ }^{1}$; Stephanie Dixon ${ }^{2}$ \\ ${ }^{1}$ Division of Urology, Department of Surgery, Western University, London, ON, Canada; ${ }^{2}$ ICES, Western \\ University, London, ON, Canada; ${ }^{3}$ Division of Urology, University of Toronto, Toronto, ON, Canada; \\ ${ }^{4}$ Division of Epidemiology and Biostatistics, Western University, London, ON, Canada
}

Acknowledgement: This work was made possible by generous support from the MacMaster Fund for Urology through St. Joseph's Health Care Foundation. This study was supported by the ICES Western site. ICES is funded by an annual grant from the Ontario Ministry of Health and Long-Term Care (MOHLTC). Core funding for ICES Western is provided by the Academic Medical Organization of Southwestern Ontario (AMOSO), the Schulich School of Medicine and Dentistry (SSMD), Western University, and the Lawson Health Research Institute (LHRI). The opinions, results and conclusions are those of the authors and are independent from the funding sources. No endorsement by the St. Joseph's Health Care Foundation, ICES, AMOSO, SSMD, LHRI, or the MOHLTC is intended or should be inferred. Parts of this material are based on data and/or information compiled and provided by CIHI. However, the analyses, conclusions, opinions and statements expressed in the material are those of the author(s), and not necessarily those of CIHI. The authors thank IMS Brogan Inc. for use of their Drug Information Database.

Cite as: Welk B, Reid J, Ordon M, et al. Do 5 alpha reductase inhibitors decrease the risk of recurrent gross hematuria in patients who have had a transurethral prostatectomy? Can Urol Assoc J 2020 January 29; Epub ahead of print. http://dx.doi.org/10.5489/cuaj.7135

Published online January 29, 2021

$* * *$

\section{Introduction}

Benign prostatic enlargement is a common cause of urinary symptoms in aging men. Some men require a transurethral prostatectomy (TURP). Previous research has shown that use of prostate specific medication is common after TURP, despite having limited physiologic basis or evidence to support their use.(1) 5-alpha reductase inhibitors (5ARIs) are one of these medications, and they are used at some point by almost $30 \%$ of men in the first 10 years after a TURP.(1) In our experience, they are often prescribed for gross hematuria in patients who have had a TURP. Our objective was to determine if 5ARI use after an episode of post-TURP gross hematuria reduces the risk of further episodes of gross hematuria. 


\section{Methods}

We conducted a population based retrospective cohort study using data from Ontario, Canada. We first identified men who had a TURP between 2003-2016 and we excluded those with a prior TURP, prostate cancer, a bladder tumor resection, or age <66yrs (our previous work has further details on the study population, data sources, coding and methodology(2)). We then identified men who returned to the hospital/ER with gross hematuria at least 90 days after their TURP (to avoid identifying ongoing hematuria from the TURP(3)), and used the date of this initial episode of gross hematuria as the study start date. We did this to make sure all men had an episode of gross hematuria which could potentially lead to the initiation of a 5ARI. A healthcare encounter with gross hematuria was defined as a hospital, emergency room, or physician visit with a relevant ICD-10 code (R31.0), a Canadian Classification of Intervention procedure code (2PM70BA, 1PM54CATS, 1PM13BAZ9, 1PM13BAC2, 1PM52BATS, 1PM52CATS, or1QT13), or a physician billing code (Z608, E783) related to hematuria.

Our primary exposure was the use of 5ARIs (finasteride or dutasteride) based on the Ontario Drug Benefits database.(4) We treated the use of 5ARIs as a time-varying exposure. This means that we accounted for men coming on and off the 5ARI, and men could have several distinct periods of 5ARI utilisation. Continuous usage was defined as $1.5 \mathrm{x}$ the duration of the prescription; if another prescription was filled within this time period the usage period was extended in a similar manner. Men were considered to be exposed to the 5ARI after the first 30 days of use through to the end of the period of continuous usage. We choose a 30-day wash-in period to account for the delayed effect of 5ARIs.(5) Each man was observed from the initial period of gross hematuria until censoring at death, emigration, treatment of prostate cancer, repeat TURP, or March 31, 2018. The primary outcome was a subsequent episode of gross hematuria (defined as above). We measured this outcome as a repeated event, and considered events $>7$ days apart as distinct episodes of gross hematuria.

Our primary analysis (SAS version 9.4, SAS Institute, Cary, NC) used an adjusted Anderson-Gill proportional hazards model to evaluate the association between 5ARI utilization and gross hematuria.(6) We did two post-hoc sensitivity analyses. First, we excluded men who were considered significant outliers from the model (those with $\geq 8$ gross hematuria outcomes) to ensure the results were not driven by this small subset of the cohort. Second, we conducted an analysis that considered only the time to the first episode of recurrent gross hematuria. A pvalue $<0.05$ was considered significant. The use of data in this project was authorized under section 45 of Ontario's Personal Health Information Protection Act, which does not require review by a Research Ethics Board. 


\section{Results}

There were 9,449 men who had at least one episode of gross hematuria post-TURP (representing $19 \%$ of eligible patients who had a TURP). The median age was 80 (Q1-Q3 75-85), and most $(77 \%)$ had undergone an electrosurgical TURP (table 1). Among this group of men post-TURP with an initial episode of gross hematuria, there were 2,713 (29\%) who used a 5ARI. We observed that 2,752/9,449 (29.1\%) men had at least 1 additional future healthcare encounter for gross hematuria (1,695 (61.6\%) had only a single event, 567 (20.6\%) had two events, and 490 $(17.8 \%)$ had three or more events).

Our primary adjusted analysis showed that 5ARI users had an increased rate of healthcare encounters for gross hematuria compared to non-5ARI users (event rate 6.63 versus 5.70 per 10,000 person-years respectively, adjusted HR 1.22, $\mathrm{p}<0.01$ ). However, two sensitivity analyses suggested no significant association between 5ARI use and future episodes of gross hematuria (table 2). We explored the reason why there might have been an increased risk associated with 5ARIs (contrary to our hypothesis), and found men who used 5ARIs were significantly more likely to undergo a second TURP, which we considered a censoring event (adjusted HR 1.54, 95\% CI 1.36-1.74, p<0.01).

\section{Discussion}

We did not find that 5ARI use among men with an episode of gross hematuria post TURP reduced the rate of repeat episodes of gross hematuria requiring medical attention compared to non-5ARI users. The possible increased risk of gross hematuria with use of 5ARIs was likely driven by a small number of men with a high number of repeated episodes of gross hematuria, and our sensitivity analysis did not support a significant association between 5ARI and gross hematuria in this population. TURP (a competing treatment for gross hematuria) was more common in 5ARI users and this suggests that the true HR from the primary analysis is $<1.22$ (closer to a null association).(6) The use of 5ARIs after TURP is common, however their efficacy is not proven. A single RCT did not show any benefit with 5ARIs in terms of reducing the rate of repeat TURP or bleeding or improving voiding.(7) Chart review studies have suggested that risk factors for early postoperative gross hematuria following endoscopic prostate resection or vaporisation may include large prostate size, use of anticoagulation, and younger age, and the benefit of 5ARIs during this initial period is inconsistent. $(8,9) \mathrm{We}$ feel that the evidence for gross hematuria reduction in operation-naïve prostates(10) and during TURP(5) should not be automatically extrapolated to the post-TURP period. Given the lack of evidence supporting the use of 5ARIs after TURP, and their potential adverse effects(11) their use should be further evaluated in clinical trials specific to this clinical scenario.

Limitations of our work include the fact that we could not measure all relevant baseline characteristics (such as volume of prostate or resected tissue), and we relied on filled prescriptions as a surrogate of medication utilisation. Administrative data could only identify men who sought medical care for gross hematuria, which likely skewed towards more severe 
cases of gross hematuria. We could not identify the clinical reason why 5ARIs were prescribed. Final, residual confounding may be present, as the use of 5ARI after TURP is likely not a random process. 


\section{References}

1. Campbell J, Reid J, Ordon M, Welk B. The Utilization of Benign Prostatic Hyperplasia and Bladder-Related Medications After a Transurethral Prostatectomy. Urology. 2019 Aug;130:126-31.

2. Welk B, Reid J, Ordon M, Razvi H, Campbell J. Population-based assessment of retreatment and healthcare utilisation after photoselective vaporisation of the prostate or electrosurgical transurethral resection of the prostate. Bju Int. 2019 Dec;124(6):1047-54.

3. Olapade-Olaopa, Solomon, Carter, Ahiaku, Chiverton. Haematuria and clot retention after transurethral resection of the prostate: a pilot study. Brit J Urol. 1998;82(5):624-7.

4. Levy AR, O'Brien BJ, Sellors C, Grootendorst P, Willison D. Coding accuracy of administrative drug claims in the Ontario Drug Benefit database. The Canadian journal of clinical pharmacology = Journal canadien de pharmacologie clinique. 2003;10(2):67-71.

5. Zhu Y-P, Dai B, Zhang H-L, Shi G, Ye D-W. Impact of preoperative $5 \alpha$-reductase inhibitors on perioperative blood loss in patients with benign prostatic hyperplasia: a meta-analysis of randomized controlled trials. Bmc Urol. 2015;15(1):47.

6. Lau B, Cole SR, Gange SJ. Competing Risk Regression Models for Epidemiologic Data. Am J Epidemiol. 2009;170(2):244-56.

7. Qian X, Yu G, Qian Y, Xu D, Liu H, Kong X, et al. Efficacy of $5 \alpha$-reductase inhibitors for patients with large benign prostatic hyperplasia $(>80 \mathrm{~mL})$ after transurethral resection of the prostate. The aging male : the official journal of the International Society for the Study of the Aging Male. 2015;18(4):238-43.

8. Jackson RE, Casanova NF, Wallner LP, Dunn RL, Hedgepeth RC, Faerber GJ, et al. Risk Factors for Delayed Hematuria Following Photoselective Vaporization of the Prostate. J Urology. 2013;190(3):903-8.

9. Yee C-H, Wong JH-M, Chiu PK-F, Teoh JY-C, Chan C-K, Chan ES-Y, et al. Secondary hemorrhage after bipolar transurethral resection and vaporization of prostate. Urology Ann. 2016;8(4):458-63.

10. Foley SJ, Soloman LZ, Wedderburn AW, et al. A prospective study of the natural history of hematuria associated with benign prostatic hyperplasia and the effect of finasteride. $\mathrm{J}$ Urol 2000;163(2):496-8.

11. Harrell MB, Ho K, Te AE, Kaplan SA, Chughtai B. An evaluation of the federal adverse events reporting system data on adverse effects of 5-alpha reductase inhibitors. World J Urol. 2020;1-7. 
Figures and Tables

\begin{tabular}{|c|c|c|c|c|}
\hline & & $\begin{array}{l}\text { No 5ARI use } \\
\text { after the initial } \\
\text { episode of gross } \\
\text { hematuria }\end{array}$ & $\begin{array}{l}\text { 5ARI use after } \\
\text { the initial } \\
\text { episode of gross } \\
\text { hematuria }\end{array}$ & $\mathbf{p}$ \\
\hline & & $\mathrm{n}=6736$ & $\mathrm{n}=2713$ & \\
\hline $\begin{array}{l}\text { Age, median } \\
\text { (Q1-Q3) }\end{array}$ & & $80(75-85)$ & $80(75-85)$ & 0.251 \\
\hline \multicolumn{5}{|c|}{ Characteristics at the time of the TURP } \\
\hline $\begin{array}{l}\text { TURP at an } \\
\text { academic } \\
\text { hospital }\end{array}$ & & $788(11.7 \%)$ & $399(14.7 \%)$ & $<0.001$ \\
\hline $\begin{array}{l}\text { Gross hematuria } \\
\text { in year prior to } \\
\text { TURP }\end{array}$ & & $2,217(32.9 \%)$ & $918(33.8 \%)$ & 0.388 \\
\hline \multirow{3}{*}{$\begin{array}{l}\text { Type of TURP } \\
\text { Procedure }\end{array}$} & Electrical & $5294(78.6 \%)$ & $2028(74.8 \%)$ & $<0.001$ \\
\hline & Laser & $670(10.0 \%)$ & $378(13.8 \%)$ & \\
\hline & Unknown & $772(11.5 \%)$ & $307(11.3 \%)$ & \\
\hline $\begin{array}{l}\text { Cystolithopaxy } \\
\text { with TURP }\end{array}$ & & $606(9.0 \%)$ & $293(10.8 \%)$ & 0.007 \\
\hline Diabetes & & $1496(22.2 \%)$ & $592(21.8 \%)$ & 0.681 \\
\hline $\begin{array}{l}5 \text { ARI use in the } \\
6 \text { months prior to } \\
\text { TURP }\end{array}$ & & $1580(23.5 \%)$ & $1190(43.9 \%)$ & $<0.001$ \\
\hline \multicolumn{5}{|c|}{ Characteristics at the time of the first episode of gross hematuria } \\
\hline $\begin{array}{l}\text { 5ARI use in the } \\
3 \text { months prior } \\
\text { gross hematuria }\end{array}$ & & $115(1.7 \%)$ & $1,086(40.0 \%)$ & $<0.001$ \\
\hline $\begin{array}{l}\text { Time since } \\
\text { initial TURP, } \\
\text { median years, } \\
\text { (Q1-Q3) }\end{array}$ & & $3(1-5)$ & $3(1-6)$ & 0.009 \\
\hline $\begin{array}{l}\text { Anticoagulant } \\
\text { use in the } 3 \\
\text { months prior } \\
\text { gross hematuria }\end{array}$ & & $148(2.2 \%)$ & $60(2.2 \%)$ & 0.966 \\
\hline
\end{tabular}

5ARI: 5 alpha reductase inhibitors; TURP: transurethral prostatectomy. 


\begin{tabular}{|c|c|c|}
\hline & 5ARI utilization & $\mathbf{p}$ \\
\hline Primary analysis ${ }^{*}$ & HR $1.22(1.05-1.43)$ & 0.009 \\
\hline \multicolumn{3}{|l|}{ Sensitivity analysis ${ }^{*}$} \\
\hline $\begin{array}{l}\text { 1. Primary analysis with exclusion of } 59 \\
\text { (representing } 2.14 \% \text { ) men in the } 99.5 \\
\text { percentile of gross hematuria episodes ( } \geq 8 \\
\text { during followup) }\end{array}$ & HR $1.12(1.00-1.25)$ & 0.051 \\
\hline $\begin{array}{l}\text { 2. Primary analysis considering only the time } \\
\text { to first episode of gross hematuria }\end{array}$ & HR $1.04(0.93-1.17)$ & 0.457 \\
\hline
\end{tabular}

The reference category for all analyses is men not using 5ARI medications. *All analyses were adjusted for the following covariates: 5ARI exposure, age, fiscal year, academic hospital, gross hematuria in year prior to TURP, type of TURP, cystolithopaxy with TURP, diabetes, 5ARI use in the 6 months prior to TURP, 5ARI use in the 3 months prior to gross hematuria, time since initial TURP, anticoagulant use in the 3 months prior gross hematuria. ${ }^{* *} \mathrm{~A}$ total of 59 men experienced $\geq 8$ episodes of gross hematuria; $45.8 \%$ and $54.2 \%$ were removed from the analysis in the 5ARI and non-5ARI groups, respectively, for this sensitivity analysis. 5ARI: 5 alpha reductase inhibitors; HR: hazard ratio; TURP: transurethral prostatectomy. 